\title{
SHANGHAI IN THE NEW ECONOMY OF GLOBAL FLOWS SHAPING URBAN FORM AND CONNECTEDNESS IN THE DIGITAL AGE
}

\author{
Serge SALAT \\ Urban Morphology and Complex Systems Institute, 16 rue de la Glacière, 75013, Paris, France \\ E-mail:serge.salat@gmail.com
}

Received 10 October 2016; accepted 22 March 2017

\begin{abstract}
This paper is a contribution to the significant research program having developed around the concept of the global city over the last four decades in urban sociology and in political geography. Global cities can be defined both as places and as locations in a network of flows. We use a network and complexity theory perspective to contribute to the debate about global cities and we apply this approach to a rising global city: Shanghai. Cities are networks from which locations emerge, and global cities are the places that emerge as interconnected command centres in the most dynamic and connected nodes in the global network of flows. As places, global cities present a highly unequal landscape of economic growth at intra-urban scale, with peaks of extreme concentration of wealth creation in specific locations within their urban space. To acquire a similar intensity of agglomeration economies in high-end services and in finance as global cities such as London, New York, Tokyo, Seoul, Singapore, and Hong Kong, Shanghai spatial structure needs more concentration and a more complex articulation of its economic densities. Pareto distributions, which are the "signature" of complexity, are the hidden order of the spiky spatial economic landscapes of global cities, for the distribution of people, jobs, and economic densities, office space density, accessibility to jobs, rents, subway network centralities. Within the dynamics of global networks, Shanghai challenge is to become a hub across five flows of goods, services, finance, people, and data and communication, in which Singapore and Hong Kong have acquired dominant positions as waypoints. The transformation of the global landscape of flows with an increasing growth of knowledge-based flows, cross-border flows, and digital flows puts Shanghai business model, dominated today by goods flows, at risk. Shanghai would benefit developing stronger air and Internet connectivity and building collaborative bridges with global cities.
\end{abstract}

Keywords: Shanghai, spatial economy, agglomeration economies, Pareto distributions, transit networks, global flows, digital economy.

\section{Introduction}

This paper is a contribution to the significant research program having developed around the concept of the global city over the last four decades in urban sociology and political geography (Braudel 1984; Castells 1989; Sassen 2000a, 2000b, 2000c, 2005). Global city theory first developed in the 1980s, initially in symbiosis with world systems and dependency theory, where the key theorist was John Friedman. It then formed a close connection with theories of post-industrial society, informational capitalism and the globalization debates of the 1990s, where Manuel Castells, Saskia Sassen and Peter Taylor have been seminal figures (Curtis 2010).

Global cities are essential to processes of globalization, providing a material and infrastructural backbone for global flows, and a set of physical sites that facilitate command and control functions for a decentralized global economy (Curtis 2010). Global cities can be defined both as places and as locations in a network of flows. We use in this paper a network theory (Barabási, Albert 1999; Barabási 2002; Barabási et al. 2006) and complexity theory (Batty 2013) approach. In this approach, cities are networks from which locations emerge, and global cities are the places that emerge as command centres in the most dynamic and connected nodes in the global network of flows. This dynamic interplay of place and network has been perceived in sociological theory by Saskia Sassen: "The global city and the network of these cities is a space that is both place-centred in that it is embedded in particular and strategic locations; and it is trans-territorial because 
it connects sites that are not geographically proximate yet are intensely connected to each other" (Sassen 2005). Global cities exhibit a set of core parallel material changes to their form. Distinctive global city morphology takes the shape of the reinvigoration of the central business district, the taking up of a nodal position within trans-territorial global city networks, and the parallel emergence of transnational global city regions (Sassen 1991).

Shanghai is such a global city region, which has the size of a country. Within a 300-km radius, Shanghai anchors and connects by High Speed Rail (HSR) the population of Germany or twice the population of Korea. The density and proximity of goods, people and ideas found in Shanghai has the potential for generating scale and agglomeration economies, leading to increases in productivity driving growth. If Shanghai succeeds in its transition to a knowledge economy and becomes a waypoint in the new economy of global flows, the city is likely to enter within the next decades in the top five global urban economies in the wake of the rise of China to top global economy, with $20 \%$ share of world GDP by 2050 . Increased connectedness to the world and integration across scales and across dimensions of global flows (goods, services, finance, data, people) are needed to strengthen the emergence of Shanghai as a global city. We examine in this paper Shanghai both as a place and as a node in the network of global flows and compare its spatial structure and its nodal strength to those of other global cities.

Our first section introduces our specific methodology to develop with quantifiable spatial analysis of economic concentration and with network theory the concept of global city. Our second section examines Shanghai as a place of economic concentration and compares its spatial economy to those of leading global cities. Our third section examines Shanghai strengths and weaknesses in the network of global flows. Our conclusion stresses the interdependence of global cities and embraces a logic of cooperation and complementarity rather than competition.

\section{Theoretical framework: the contribution of com- plexity and network theory to a mathematical understanding of the concept of global cities}

\section{The global city: introducing a concept}

"National and global markets as well as globally integrated organisations require central places where the work of globalization gets done. Finance and advanced corporate services are industries producing the organisational commodities necessary for the implementation and management of global economic systems. Cities are preferred sites for the production of these services, particularly the most innovative, speculative, internationalised service sectors. Further, leading firms in information industries require a vast physical infrastructure containing strategic nodes with hyper-concentration of facilities" (Sassen 2005).

Theoretically, comparing an emerging global city, Shanghai, to established global cities, such as New York, London, Tokyo, Singapore, and Hong Kong, the paper addresses two key issues in the debate about globalisation: the dynamics of networks and places. Cities are networks from which locations emerge (Batty 2013). The shortest definition of a global city is to be an emerging location of the global network. Global cities can be defined as the most important and integrative nodes in the network of global flows: they dominate the networks of flows and are central (in the sense of network theory) across many dimensions of flows. This is true at all scales and explains the spatial intra-urban structure of global cities, which is also extremely concentrated and shaped by transit accessibility to extreme concentrations of jobs and economic density $\left(\mathrm{GDP} / \mathrm{km}^{2}\right)$. At intra-urban scale, in cities like London, New York, or Tokyo, centrality in public transportation networks structures extraordinary sharp gradients of economic concentration. The global functions of the city are not spread out across the urban space: they are concentrated in very limited areas of $15 \mathrm{~km}^{2}$, concentrating 1.5 million jobs in New York and London, and presenting extreme peaks of economic density that spur agglomeration economies in finance and in advanced and creative services industries. The paper explores these dynamics of networks and flows in global cities in innovative ways, bringing into the debate initiated by Saskia Sassen the analytical approach of complex systems theory.

\section{Pareto distributions, the spatial structure of economic concentration and the structure of networks}

It is visible that the Square Mile of the City of London concentrates a disproportionate part of economic power in an extreme spike. The Square Mile of the City of London generated $£ 45$ billion in economic output in 2014, equivalent to $14 \%$ of London's output on $0.2 \%$ of its land area, and 3\% of UK's total GDP. The cascade of spikes within spikes, with inner London spiking also extremely high within Greater London and concentrating 70\% of its GDP on 10\% of its surface (Salat et al. 2017), points to a fundamental property of urban economy spatial patterns: that there are Pareto distributions in the distribution of 


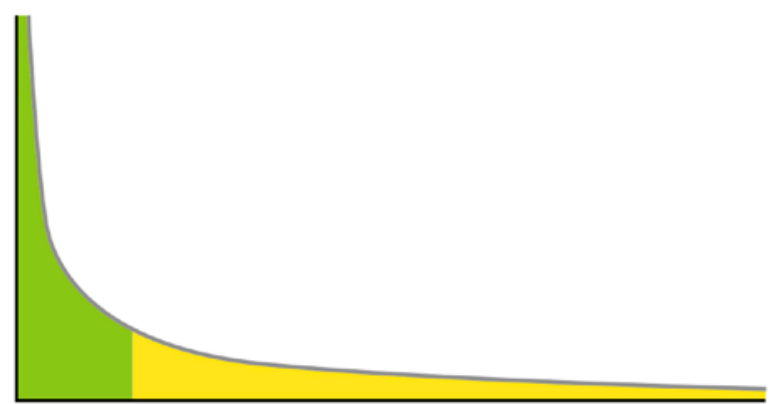

Fig. 1. Pareto distributions: the hidden order of spiky economic landscapes and of networks at all scales. The spatial distribution of the wealth of cities, as well as of people, jobs, and economic densities, office space density, accessibility to jobs, rents, subway network centralities, and so on, across the urban space (Salat, Bourdic 2015; Salat et al. 2017; Salat, Ollivier 2017) follow skewed distributions that are modelled by inverse power laws known in economy for a long time under the name of Pareto distributions. They comprise a few large and very large values (in green on the left) and a "long tail" of small values on the right

wealth and economic concentration at all scales. The Pareto distribution, shown in Figure 1, named after the Italian civil engineer, economist, and sociologist Vilfredo Pareto, is a power law probability distribution that is used in the description of social, scientific, geophysical, actuarial, and many other types of observable phenomena. Pareto originally used this distribution to describe the allocation of wealth among individuals (Pareto 1896) since it seemed to show rather well the way that a larger portion of the wealth of any society is owned by a smaller percentage of the people in that society. He also used it to describe the distribution of income. As our study show, urban space is fundamentally an economic space structured by competition and interdependence and many of its characteristics follow Pareto distributions. In a city, for example, the density of jobs is high in a few locations, medium in a moderate number of locations, and low in a large number of locations, and this obeys quite precise mathematical regularities. The frequency of a component of size (or density, concentration, connectivity, productivity) $x$ is proportional to the inverse of its size at an exponent $m$ characteristic of the system. The relative frequency of each type is determined by the mathematics of the rank-size distribution: the size of any urban component (density, accessibility, connectivity, productivity) is related to its rank within the distribution. The higher $m$, the steeper the gradient between the few high values and the many low values. An inverse power law distribution does not have a central peak, like the familiar bell curves found in statistics. It is a continuously decreasing curve, indicating that many small observations coexist with a few large ones in a highly structured mathematical way that relates the large, the intermediate, and the small.

Research by the Urban Morphology and Complex Systems Institute (Salat 2017) documents the presence of power laws at intra-urban scale, where they order the patterns of most urban values and their distribution across urban space. We have demonstrated that a wide array of densities and productivities when analysed spatially on disaggregated sets of data follow Pareto distributions. These urban characteristics include: people and jobs densities, numbers of people and jobs accessible from any location in the city, office space density, rents and property prices, degree and betweenness centrality in the subway network, energy density (energy use per unit of land), energy productivity (energy used per unit of GDP produced) (Salat 2017). For a study of efficiency in global cities, mention should be made of energy productivity (E/GDP). Although finance and high-end services are extremely energy intensive, the economic productivity of energy is higher in dense concentrations of finance and high end service jobs connected to the global economy as suggested by empirical studies in London. energy productivity. The gross value added per unit of energy spent is unequally distributed across London urban space. $41 \%$ of GVA is generated on $4.5 \%$ of the land area $\left(72 \mathrm{~km}^{2}\right)$ with $19 \%$ of the energy (Salat 2017).

We can split Economic productivity into 2 components:

$$
\begin{aligned}
& \text { Economic productivity }=\frac{\text { Gross Value Added }}{\text { Nb of Jobs }}= \\
& \frac{G V A}{\text { Energy }} \times \frac{\text { Energy }}{\text { NBof Jobs }},
\end{aligned}
$$

Economic productivity $=$ Energy produvtivity $\times$ Job energy intensity.

Following this decomposition of economic productivity, economic productivity in the Square Mile of City of London is almost the double than that in Greater London without the City. Energy productivity (GVA/energy) is 6 times higher in the City than in the rest of Greater London, while job energy intensity (energy per job) is less than one third. The City of London is an extreme case but it demonstrates clearly that high peaks of jobs densities in advanced services economy lead to a very efficient use of energy in spite of being associated to high spikes of energy use. This analysis concerns building energy and should be completed by transportation energy. Previous work by the Urban Morphology and Complex Systems Institute at borough level in London, at arrondissement level 
in Paris, and district level in New York has shown that high local density reduces transportation energy (Bourdic 2011).

The new science of networks has shown that Pareto distributions are also intrinsic to the various attributes of a network such as the size, number, centrality and connectivity of its elements (Barabasi, Albert 1999). Further research on cities has shown that the same property characterises the flows that move across urban networks (Batty 2013; Salat, Bourdic 2015; Salat 2017). Thus, the intrinsic economic concentration of spaces and places from micro intra-urban scale to global scale reflects the hierarchy of nodes in networks and in flows at all scales. As summarized by Michael Batty, "in essence, the distribution of elements that compose the city - the hubs or nodes that sustain them - present us with highly skewed distributions, reflecting the essential economic processes of competition that drive a city's functions and determine its form and structure (Batty 2013)". These inverse power laws reflect processes of scale, which in some sense are self-similar. This signature of a system's function implies that the system's subsystems, components and elements, are ordered and connected hierarchically. These scaling processes generate urban growth and underpin the city's evolutionary architecture, opening up our theory and model to a world of complexity; from forms that associate a high level of order in their macro-structure to forms with a high level of diversity and randomness in their details (Batty 2013).

\section{The hierarchy of global cities: Pareto distributions in the global landscape of the wealth of cities}

The global landscape of the wealth of cities is like the wealth of nations and individuals. The global economy is structured spatially by the mathematical laws of economic inequality. Today, the six dominant global cities in terms of GDP are in this order: Tokyo, New York, Los Angeles, Seoul, London, and Paris. They concentrate about $8 \%$ of the world GDP. New York and London together control almost equally $40 \%$ of the world financial transactions. Tokyo's GDP is the same as an entire continent, Australia. The global landscape of growth is also concentrated. The top 100 cities ranked by their contribution to global GDP growth in the next 10 years will contribute just over 35\% of GDP growth to 2025 (Dobbs et al. 2011). Recent research by the Urban Morphology and Complex Systems Institute has found the mathematical regularity behind the spiky landscape of global urban economies inequality. An inverse power law of exponent -0.6 structures the global landscape of urban global wealth, as shown in Figure 2.

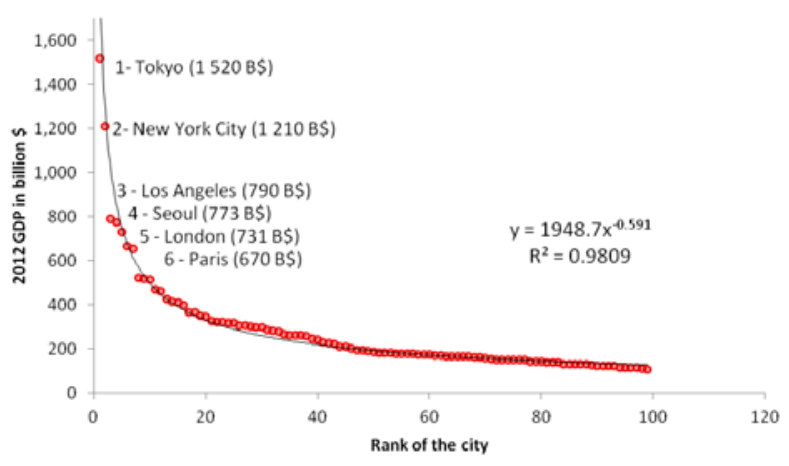

Fig. 2. The wealth of the 100 wealthiest cities ranked in the order of wealth follows an inverse power law of exponent -0.6 . The hierarchy of cities wealth is steep. The top 100 cities concentrate $38 \%$ of the global GDP. The top 10 cities concentrate $11 \%$ of the global GDP. Tokyo GDP is equal to Australia GDP. New York GDP is almost equal to Korea GDP. If Tokyo were a country, it would be the $12^{\text {th }}$ economic power. If New York were a country, it would be the $15^{\text {th }}$ economic power

Source: Salat 2015. Data: Brookings Institution.

\section{The spatial structure of global cities: Pareto distributions in the concentration of the space economy}

The underlying mathematical structure of the space economy in global cities presents mathematical regularities identical in New York and London, which demonstrate a form of "universality" in the space economy concentration of the most dynamic, evolving, competitive, and global cities. More precisely, in statistical mechanics, a "universality class" is a collection of mathematical models, which share a single scale invariant limit. While global cities, such as Paris, London, and New York, may differ dramatically at small scales, their behaviour becomes increasingly similar as the limit scale is approached. In particular, asymptotic phenomena such as critical exponents in inverse power laws are the same for all cities in the class ${ }^{1}$ (Salat 2017). In our empirical studies of the structure of urban space in global cities, we find the same values of exponents in the Pareto distributions that organise the concentration of economic densities in urban space (Salat 2017). As if, for urban spaces, some economic efficiency principle of organisation was at work, a principle deriving from the structure of networks and flows, that in many large systems, from natural to engineered like the Internet, are also structured according to Pareto distributions (Barabási, Albert 1999).

Distribution of economic densities in global cities clearly follows Pareto distributions. The command

\footnotetext{
1 Studies of cities as percolation systems with phase transition points may explain these universality classes in urban systems.
} 


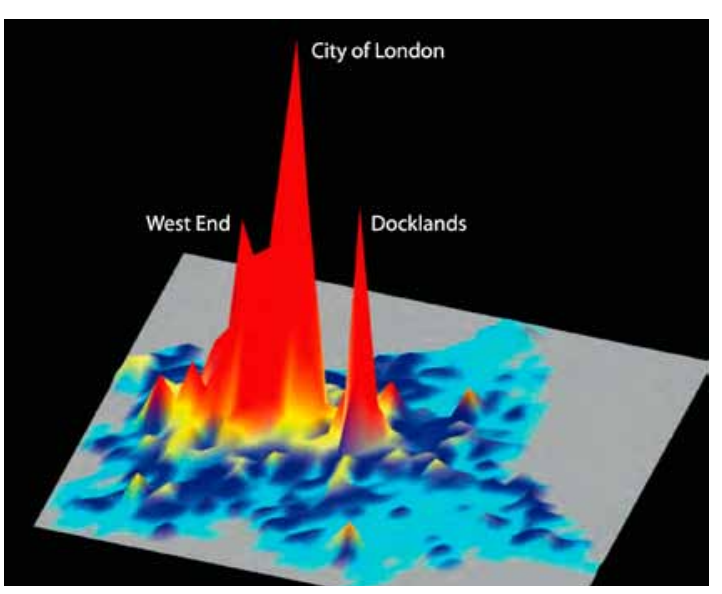

Fig. 3. London energy landscape is characterized by a high spike of energy density (here electricity per unit of land) of more than $300 \mathrm{MW} / \mathrm{km} 2$ in the City of London. Courtesy: City of London.

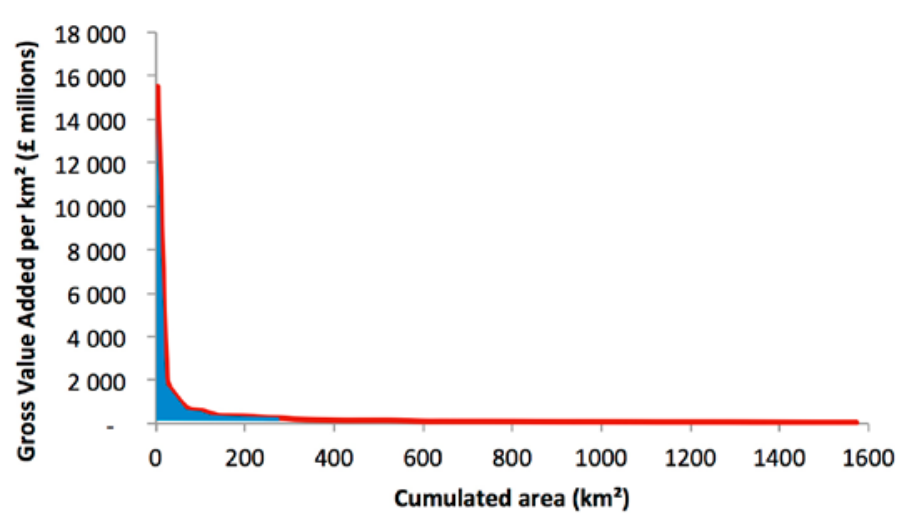

Fig. 4. Spatial distribution of the density of GDP $\left(\mathrm{GDP} / \mathrm{km}^{2}\right)$ in London (at borough level granularity), here ranked from the most productive areas $/ \mathrm{km}^{2}$ to the less productive, follows an inverse power law of exponent -0.9 . $70 \%$ of the GDP is produced on $20 \%$ of the land area, in Inner London

Source: Salat 2017.

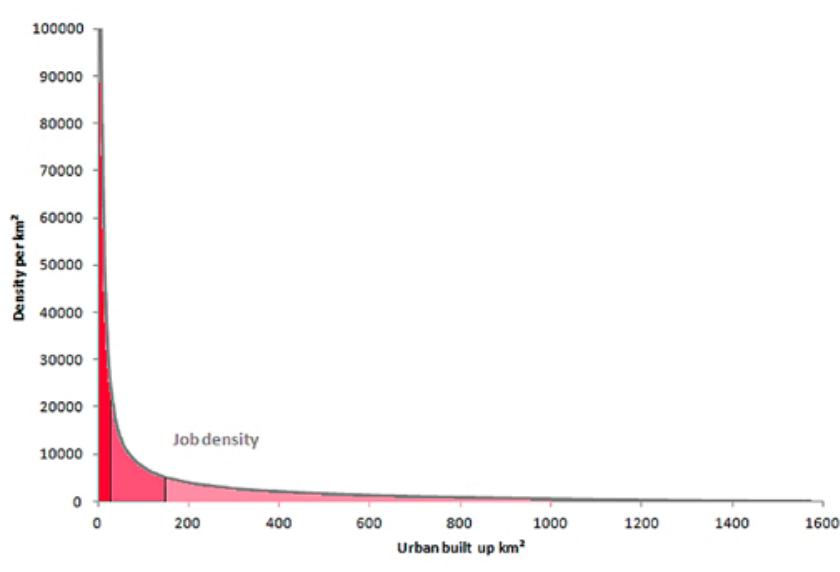

Fig. 5. London job density ranked from the densest areas to the less dense shows an inverse power law of exponent 1. The area under the curve is the total number of jobs in London. Within the spike on the left, one third of London jobs (1.5 million jobs) are concentrated in $15 \mathrm{~km}^{2}$ at an average density of 100,000 jobs $/ \mathrm{km}^{2}$ peaking at 150,000 in the City of London. In the long tail on the right, another third is dispersed at a density of $1,071 \mathrm{jobs} / \mathrm{km}^{2}$ on $1,408 \mathrm{~km}^{2}$. The middle part of the curve contains the median third with 1.5 million jobs in $150 \mathrm{~km}^{2}$ at a density of 10,000 jobs $/ \mathrm{km}^{2}$ Source: Salat 2017.

centres of the world economy are highly concentrated in a few square kilometres as shown in Figure 3 showing the spiky landscape of London energy use per unit of land (which is a proxy of the intensity of land use), in Figure 4 showing the Pareto distribution of GDP produced per unit of land in London, and in Figure 5 showing the spatial distribution of jobs in London. Extreme concentration of economic power in a few global cities is accompanied by extreme concentration of economic power within a few square kilometres of these global cities. Within global cities, roughly $20 \%$ of the urban land produces $80 \%$ of a city's GDP, following a Pareto

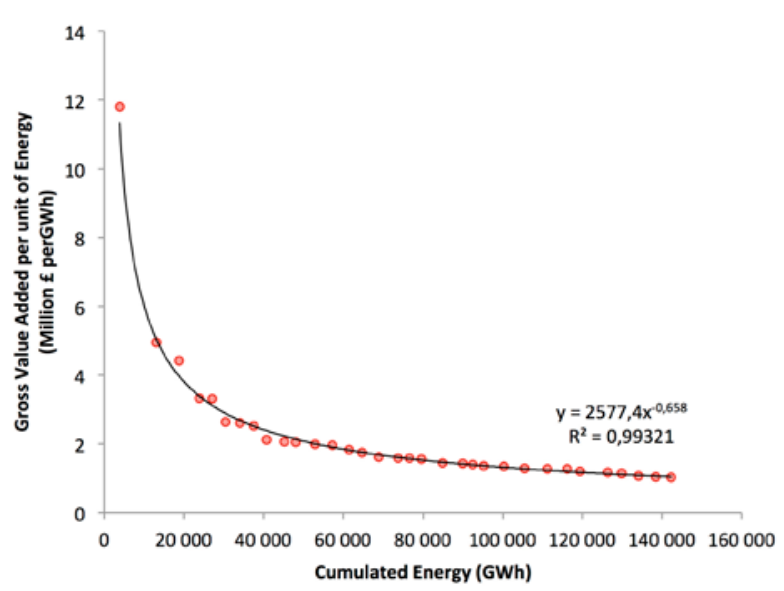

Fig. 6. Energy productivity (GVA/Energy) in London follows an inverse power law distribution with a few highly efficient boroughs and a long tail of less and less efficient boroughs. Each unit of energy is ranked on the $x$-axis from the most economically productive to the less economically productive. The area under the curve is the total London GVA Source: Salat 2017.

principle. Inner London with $20 \%$ of Greater London area produces $70 \%$ of its $\mathrm{GVA}^{2}$ and concentrates $56 \%$ of all Greater London private sector jobs.

The command functions within global cities are extremely concentrated with $29 \%$ of Inner London office space concentrated in less than $1 \%$ of its area, in the City of London $\left(450,000\right.$ jobs in $2.9 \mathrm{~km}^{2}$ with a growth of $30 \%$ during the last decade). Concentration increases productivity and energy productivity as shown in Figure 6. Productivity per job in the City of London is

2 In 2009, Outer London produced 83 billion $\mathfrak{E}$ GVA and Inner London 186 billion $\mathfrak{E}$. Source: Regional and sub-regional GVA estimates for London, (UK Office for National Statistics 2009). 


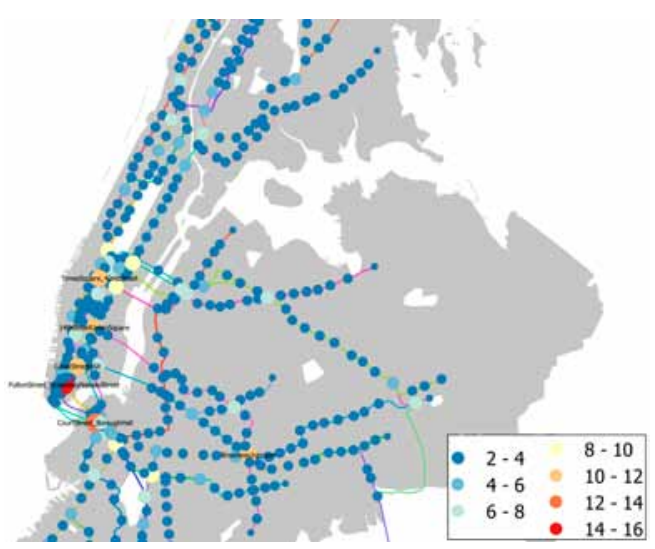

Fig. 7. Degree centralities of subway stations in New York Source: Salat, Ollivier 2017.

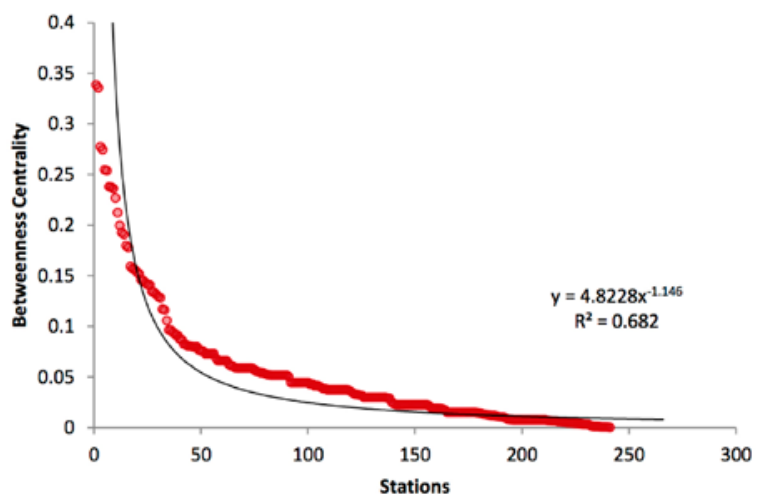

Fig. 9. Betweenness centrality of subway stations in London ranked from the most between central to the least one follows an inverse power law of exponent -1.14 Source: Salat, Bourdic 2015.

twice that of Greater London and three times that of the UK. Comparison of accessibility to public transport across Inner London with the geography of jobs density shows that quality of public transport connections is one of the factors that have a strong effect on business location choices in central London (Sivaev 2013).

\section{The shape of centralities in transit networks in global cities}

The shape of transit networks has important implications on the levels of accessibility of the different urban areas. International experience suggests first that efficient subway layouts in global cities tend to converge towards a similar layout characterized by a core and spokes structure (Roth et al. 2012). The core is densely connected with a constant density of stations, highly interconnected by crisscrossing lines, and ensures high levels of accessibility for people and companies at less than 500-metre. The core has a limited spatial extension of about 5-kilometre radius because it would be too costly to maintain a high density of stations

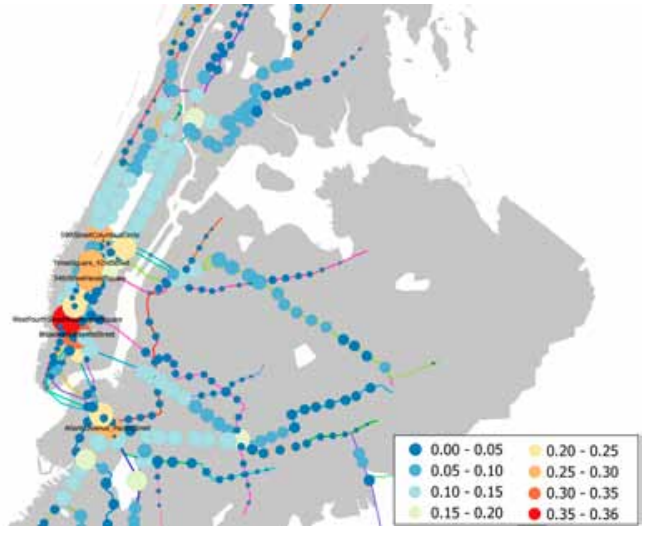

Fig. 8. Betweenness centralities of subway stations in New York Source: Salat, Ollivier 2017.

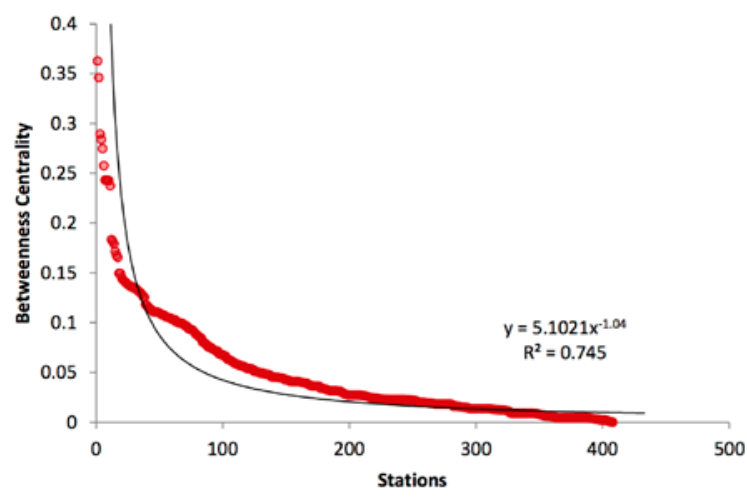

Fig. 10. Betweenness centrality of subway stations in New York City ranked from the most between central to the least one follows an inverse power law of exponent -1.04 Source: Salat, Bourdic 2015.

beyond this radius. Then, the structure changes for spokes, with a density of stations decreasing sharply ${ }^{3}$ when moving away from the city core. Thus, levels of accessibility decrease sharply when crossing the core limit. Second, "centralities" in subway networks play an important role in structuring levels of accessibility and economic opportunities.

Centralities in networks can be defined and measured precisely in many different ways, from which we can select three: degree centrality, mapped for New York in Figure 7, describes how connective a station is, that-is how many lines it connects (major interchanges have high degree centrality values); closeness centrality describes how close a station is from all the other stations in the network (closeness centrality is a measure of accessibility to a station within the network); betweenness centrality, mapped for New York

3 The sharp decrease in density of stations with distance to city
center follows an inverse power law of the form $\mathrm{R}^{-1.6}$ (Salat, Bourdic 2015). 
in Figure 8, describes how many routes go through a given station (the more routes through the network pass through a station, the more "in between" this station is). Stations that have high betweenness centrality values articulate different sub-networks (for example suburban trains and subway lines, or core and spokes in a subway network). Research has shown that degree centrality and betweenness centrality of subway stations in global cities such as Paris, London, New York, Tokyo, also follow inverse power laws, shown in Figure 9 for London and in Figure 10 for New York City, and that high degree central and between central stations have a very high potential for development (Salat, Bourdic 2015; Salat, Ollivier 2017)

\section{The networked structure of global cities}

The paper assesses the position of Shanghai within the network of global flows. Sassen (2005) hypothesis is that the global nature of the economy leads to a strengthening of cross-border city-to-city transactions and networks. What we see are not single global cities but the emergence of a transnational network of cities. Cities become global so far as they are key nodes in this global network. These global cities become increasingly disconnected from their hinterlands or even their national economies and become connected to the network of global cities, which presents highly hierarchical patterns. Global cities have shifted from material flows to flows of finance, people and data. According to the Economist Intelligence Unit (The Economist Intelligence Unit 2013), New York ( $\left.1^{\text {st }}\right)$ and London ( $\left.2^{\text {nd }}\right)$ will be the world's two most competitive cities in 2025, while Singapore $\left(3^{\text {rd }}\right)$, Hong Kong $\left(4^{\text {th }}\right)$ and Tokyo $\left(5^{\text {th }}\right)$ will retain their position as globally competitive centres.

The degree of air connectivity between cities reflects their importance as nodes in the network of global cities as shown in Figure 11 presenting main world air

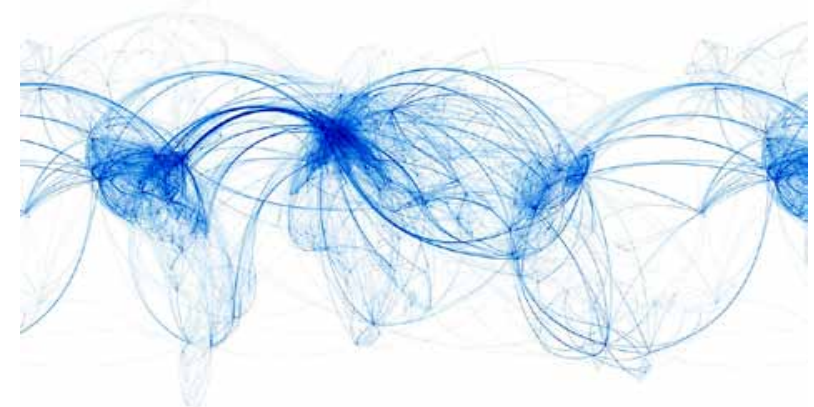

Fig. 11. Main world air traffic corridors. The evolution between 2003 (above) and 2014 (below) shows the persistent domination of New York, London and Tokyo within the space of air corridors traffic corridors. London for instance is the first international airport system in traffic terms. It reflects the fact that London is simultaneously a major business centre, a major cultural centre and a major tourist centre, and that all these are synergistic. Air traffic corridors reveal particularly strong intercontinental linkages between London, New York and Tokyo. This reflects the hierarchy and the interdependencies in the global advanced services economy ${ }^{4}$. A closer look at the air corridors map gives a more detailed perspective, showing structured networks within networks, which is the "signature" of the scale free nature of networks, embodied mathematically in Pareto distributions. In particular, three major sub-networks appear. A local multi-polarity appears within these sub networks. Europe is a network of many cities densely interconnected with air corridors. China is less densely interconnected. Asian air connectivity is dominated by Tokyo and Hong Kong, due to their role as global cities.

In the digital age, trade, finance, people and data increasingly connect the world economy. The knowledge-intensive portion of global flows increasingly dominates - and is growing faster than - capital- and labour-intensive flows.

Figure 12 shows a strong concentration of international internet routes in the hubs dominating the knowledge intensive economy, which is the economy of the future. If measured as a sector, Internet-related consumption and expenditure is now bigger than agriculture or energy. On average, the Internet contributes $3.4 \%$ to GDP in the 13 countries covered by a recent McKinsey study - an amount the size of Spain or Canada in terms of GDP (Rausas et al. 2011). Small and medium businesses heavily using Internet technologies grew and exported twice as much as competitors, while also enjoying a $10 \%$ productivity advantage. $21 \%$ of GDP growth over the past five years in mature economies was due to the Internet, a sharp acceleration from the $10 \%$ contribution over 15 years (Rausas et al. 2011) $)^{5}$. The United States retains the greatest share of the global Internet economy, 38\%, compared to 14 and

4 The air traffic network has a clear hierarchy of hubs dominated by three major hubs with a high level of "degree centrality" (number of air routes passing through a city node). New York, London, and Tokyo appear as the three major global cities. They are the world articulations, due, among others, to their role in finance, in creative industries and in high-tech and their position in the "space of flows" of the network.

5 Most of the economic value created by the Internet falls outside of the technology sector, with $75 \%$ of the benefits captured by companies in more traditional industries. The Internet is also a catalyst for job creation. Among 4,800 small and medium-size enterprises surveyed by McKinsey, the Internet created 2.6 jobs for each lost to technology-related efficiencies (Manyika et al. 2014). 

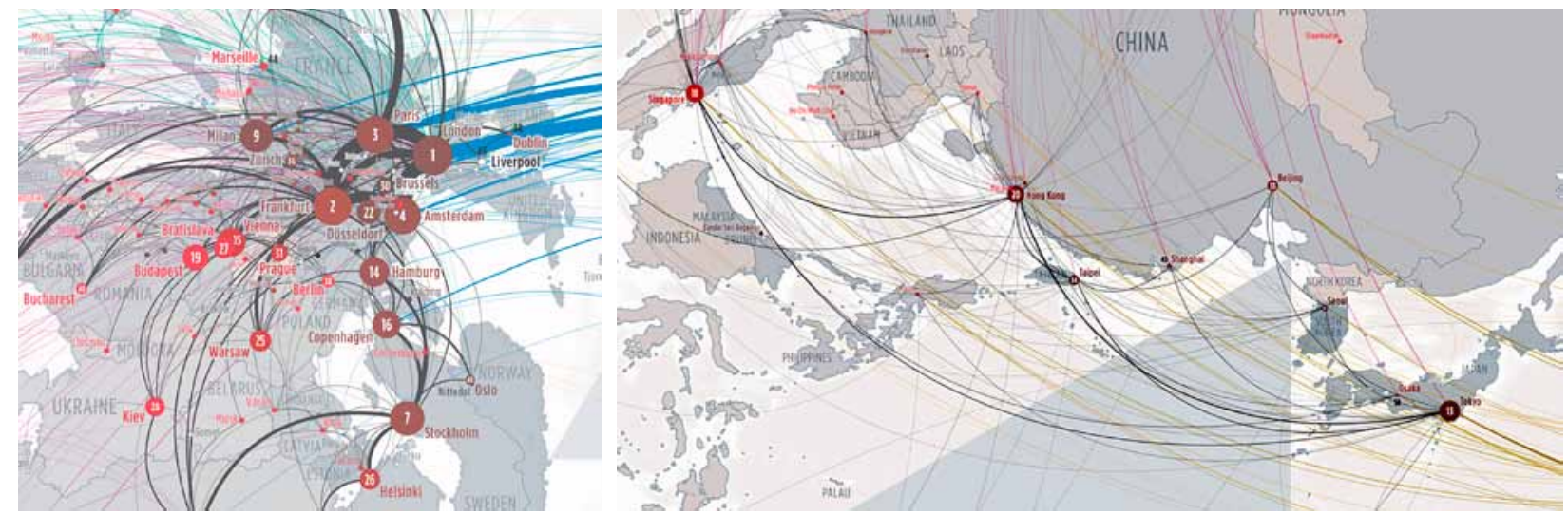

Fig. 12. International Internet routes: scaled according to bandwidth, coloured according to interregional route. Cities: scaled according to bandwidth, London is $1^{\text {st }}$, Paris $3^{\text {rd }}$, NY $5^{\text {th }}$, Tokyo $13^{\text {th }}$, Singapore $18^{\text {th }}$, Hong Kong $20^{\text {th }}$, Shanghai $45^{\text {th }}$ Source: TeleGeography.

$10 \%$ for Japan and China respectively ${ }^{6}$. Reliable and rapid access to the Internet has thus become essential for competitiveness. High-speed Internet broadband has become a basic infrastructure. Cross-border Internet traffic could increase eightfold by 2025, a key driver in addition to current momentum (Manyika et al. 2014).

\section{Shanghai as a place versus New York and Tokyo}

\section{Concentration of functions}

Sassen (2005) describes global cities in the context of the current international economic system with the growing participation of national economic actors in global markets. In this context, she proposes to rescale the strategic territories that articulate the new system. She locates the emergence of global cities against a range of instantiations of strategic scales and spatial units. Sassen states first that the geographic dispersal of economic activities that marks globalization along with the simultaneous integration of such geographically dispersed activities, is a key factor feeding the growth and importance of central corporate functions. Second, these central functions become so complex that increasingly the headquarters of large firms outsource them: they buy a share of their central functions from highly specialized service firms - accounting, legal, public relations, programming, telecommunications, and other such services. The third hypothesis of Sassen (2005) is that those specialised service firms

\footnotetext{
6 The United States is also the country with the most balanced structure, garnering relatively equal contributions from hardware, software and services, and telecommunications. The United Kingdom and Sweden are changing the game, in part driven by the importance and the performance of their telecom operators. India and China are strengthening their position in the global Internet ecosystem rapidly with growth rates of more than 20\% (Manyika et al. 2014).
}

engaged in the most complex and globalised markets are subject to agglomeration economies. The importance of speed in these transactions constitutes a new agglomeration dynamics. In this paper, we give a mathematically-based evidence of these forces of agglomeration and show that the patterns of transit accessibility, namely 20 to 30 -minute door to door by transit, shape extremely dense concentration of jobs and GDP in global cities such as London, New York, and Paris.

These types of urban environments, function like "an extremely intense and dense information loop" (Sassen 2005). Sassen (2005), sixth hypothesis is that the high number of high-level professionals and high profit making specialized services firms have the effect of raising the degree of spatial and socio-economic inequality in these cities. This paper shows that the form of this concentration of economic functions and of value creation follows inverse power laws with universal sharp spatial gradients with exponents close to -1 . These gradients of economic concentration are similar across global cities, delivering a strong signature of universality. They give insights on the level of economic concentration of corporate headquarters and outsourcing supportive firms that Shanghai may have to reach to shape its spatial structure in a similar manner as the global cities that dominate the global economy and control a large part of its economic and informational flows. Another example given below is New York.

\section{Concentration and networking of the space economy in New York}

The inner cores of global cities are extremely dense. Highly connective transit hubs link their peaks of jobs concentration. A fine grain, mixed-use urban fabric, with a dense pattern of streets and high qual- 


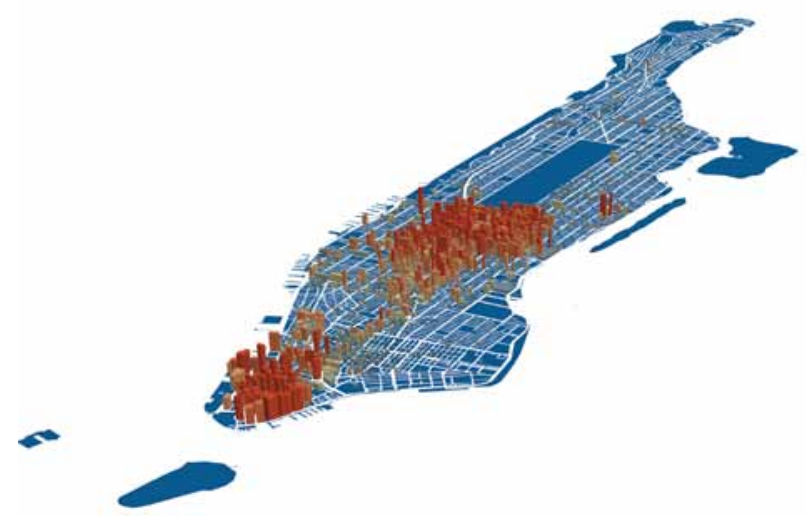

Fig. 13. 3D visualisation of office density in Manhattan Source: Salat, Ollivier 2017.

ity public space supports this density ${ }^{7}$. The high frequency of social and economic interactions found in London and New York creates a vibrant space for new ideas to flourish and innovations to take place. Agglomeration forces translate into extremely bumpy and spiky urban economic landscapes. In global cities, such as London and New York, one third of the jobs are agglomerated in about $1 \%$ of the metropolitan area (1.5 million jobs in $15 \mathrm{~km}^{2}$ of urban land at an average density of $100,000 \mathrm{jobs} / \mathrm{km}^{2}$ ) creating intense knowledge spill overs. High densities of jobs increase productivity, competitiveness and job creation. New York City presents an extraordinary concentration of office space: $60 \%$ of New York City office space is concentrated in $9 \mathrm{~km}^{2}$ in two areas in Manhattan, that is in about $1 \%$ of NYC area, as shown in Figure 13. These extreme concentrations are made liveable by high quality public space like in in the project of Hudson Yards in Manhattan (Salat, Ollivier 2017).

As already stated, cities are networks from which locations emerge. We observe a clear correlation between economic concentration, centrality in the network and sharp gradients of accessibility to jobs. In Manhattan, an average 2.6 million jobs are accessible in less than a 30 -minute public transit commute (excluding walking time), and more than $75 \%$ of commuters use transit; more than 1 million workers are accessible within a 30 -minute transit commute to an employer. Figure 14 shows the number of jobs accessible in less than 30-minute door to door by transit and walking in New York City and reveals the strong domination of Midtown as the most connected location in the city. The highest concentration of accessibility is in Midtown, which is un-

\footnotetext{
7 The two financial centers of the world, Wall Street and The City of London are in the most ancient and fine grain parts of each respective city and cover only a square mile while managing each about $20 \%$ of the financial transactions of the world.
}

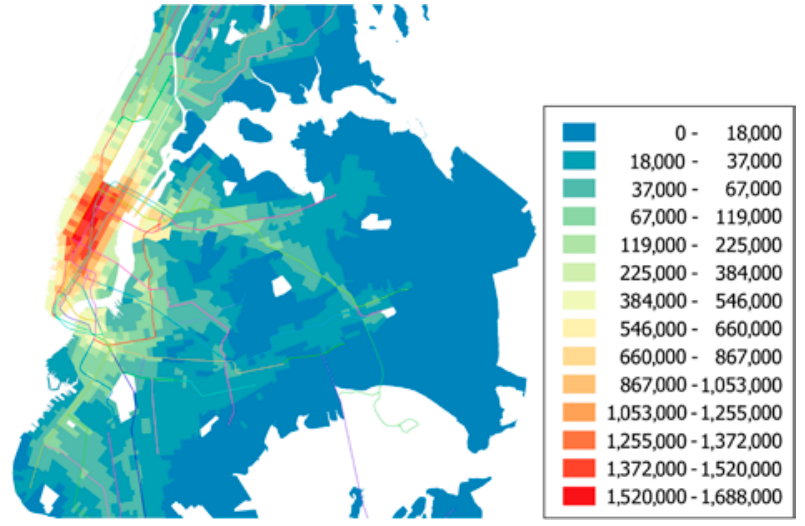

Fig. 14. Number of jobs accessible from any location in New York City in less than 30-minute door to door by transit, including walking time, in 2015. This map shows extreme variations between the spatially limited core of Manhattan giving access to 2 million jobs and a wide suburbia giving access to less than 100,000 job opportunities

Source: Salat, Ollivier 2017.

dergoing rezoning at higher density: 3.3 million jobs are accessible in less than a 30-minute transit commute, and 1.6 million workers are accessible within a 30-minute transit commute on average.

Why are these extreme concentrations of jobs and companies happening in so limited urban areas? Why 450,000 jobs in the Square Mile of City of London? And why concentration once established is growing? Cities are places where people come together to interact with one another. Cities accelerate interactions, connections, and transactions. In other terms, they are networks. The extreme concentration in Manhattan Midtown or in the City of London is an effect of this networked structure, of the need of personal face-toface contact in advanced services economies based on knowledge spill overs. People in the City of London and in Midtown Manhattan form a social network where everybody is connected to everybody else with the minimum degrees of separation. Network science has shown that when we add more links between nodes, the distance between the nodes suddenly collapses. High peaks of concentrations of jobs such as The City of London or Manhattan Midtown are "small worlds" not only in the sense that they span a limited geographical area but more deeply because the geographical proximity increases the average number of links between people and thus decreases dramatically the degree of separation between the million jobs that can be reached in less than 20-30-minute from the epicentre of concentration. Everybody becomes connected to everybody within two of three degrees of separation, creating an intense web of exchanges favouring creativity and innovation spill overs. In New York, in 
order to intensify even further this highly networked agglomeration economy in Midtown, the most accessible and interconnected area by public transport, an amendment has rezoned at high density for commercial development 73 blocks in East Midtown to capture the job growth of the two coming decades in the densest and most accessible area of NYC (New York City Department of City Planning 2013).

\section{A polycentric form of concentration in Tokyo}

International experience suggests that stations with high betweenness centrality capture important flows of passengers and have thus a high market development potential: in Tokyo, the stations along Yamanote line, shown in Figures 15 and 16, where the busiest station in the world, Shinjuku, is located with a traffic of 3.5 million passengers a day, and a booming real estate market; or Circle Line in London, with high-end urban renewal projects such as King's Cross (Salat, Ollivier 2017). Besides being a dominant mode of transportation with a market share of over $50 \%$ within Tokyo 23 wards $\left(9\right.$ million inhabitants, $\left.600 \mathrm{~km}^{2}\right)$ subway and urban rail, with their more than $6,000 \mathrm{~km}$ and 2,000 stations (at metropolitan scale) have played a decisive role in shaping Tokyo urban and economic structure $^{8}$. The integrated development of railways and their surroundings was stimulated by the fact that private railway developers owned not only the railway infrastructure but also large parts of the areas surrounding it. The suburban spokes connect to the Yamanote loop, a circular line that connects most of Tokyo's urban centres. The Yamanote line spans approximately $12 \mathrm{~km}$ North South and $6 \mathrm{~km}$ East West with an elongated shape similar to the shape of Manhattan island. All Stations are for most of them major hubs connecting also to the high-speed train. Figure 17 computed only with the Tokyo subway (excluding JR and private railway) shows the high hierarchy of hubs in central Tokyo. Figure 18 shows the hierarchy of betweenness centrality in Tokyo subway. This highly hierarchized network system has fostered high agglomeration of economic activity.

In Tokyo, the sub-centres with the highest peaks of value creation and highest densities of jobs and GDP Shinjuku, Ikebukuro and Shibuya - are concentrated along Yamanote line. This compact polycentric urban form has been created by one century of policies integrating transport and land use. Public investment has

\footnotetext{
8 During the period of enormous economic growth after World War II, it was largely the railways that facilitated the development of Tokyo. As a result, large areas of land have been developed around the railway lines that radiate outwards from the city center.
}

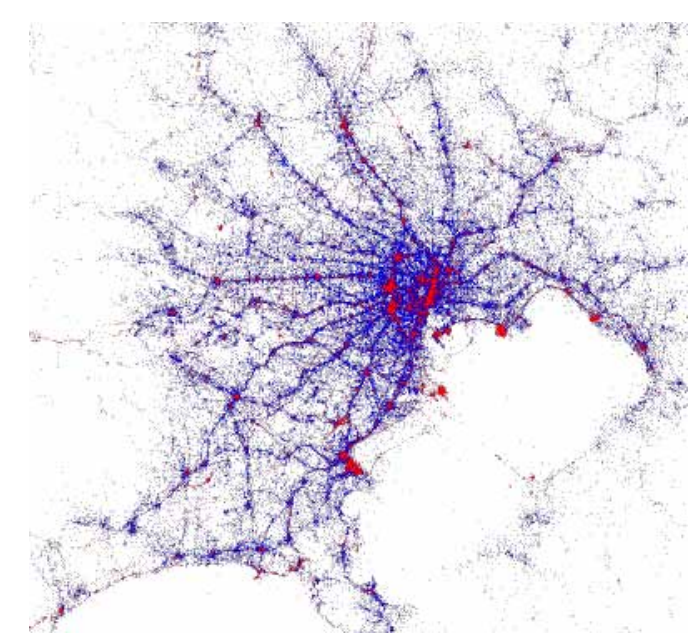

Fig. 15. The map of tweets (in blue) and Flickr (in red) activity in Tokyo by Eric Fisher reveals the compact poly-centricity of Tokyo around the $34.5-\mathrm{km}$ long Yamanote line that connects the main Tokyo economic cores

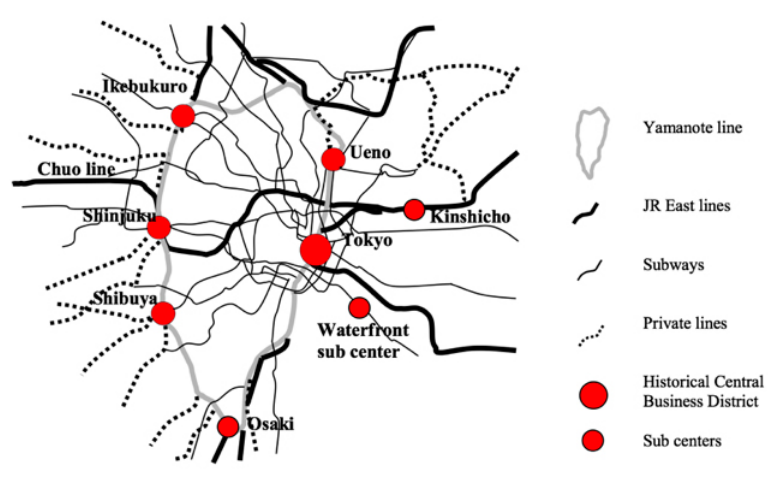

Fig. 16. Structure of Tokyo's Railway Network (Chorus, Bertolini 2011). The Yamanote line has 29 stations and encloses a relatively small area of about $60 \mathrm{~km}^{2}$ (about the same size of Manhattan) where all the economic density of Tokyo is concentrated

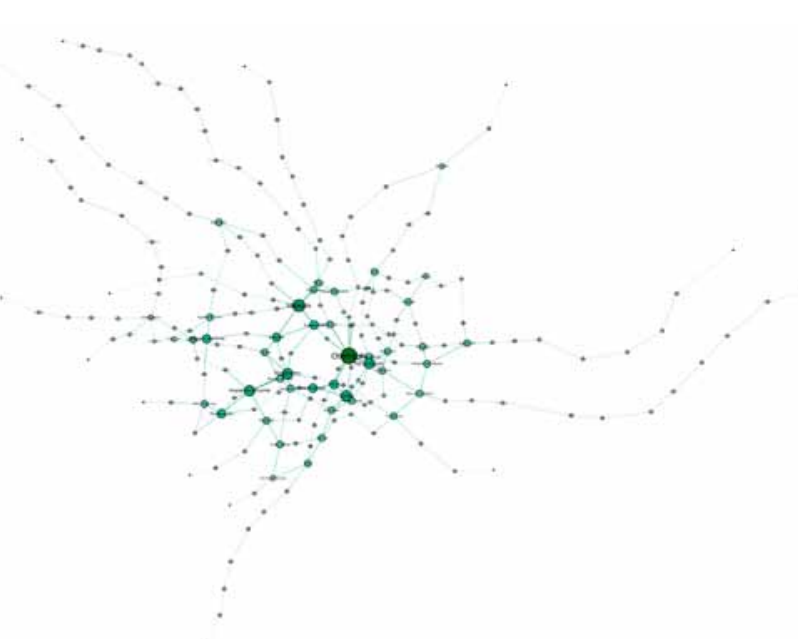

Fig. 17. Degree centrality hierarchy of Tokyo subway (calculation made without Yamanote line)

Source: Salat, Bourdic 2015. 


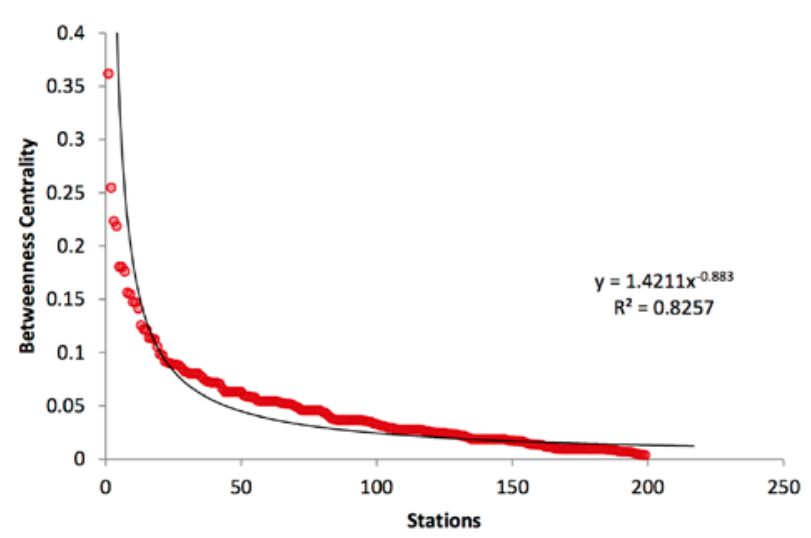

Fig. 18. Betweenness centrality hierarchy of Tokyo subway (calculation made without Yamanote line) follows an inverse power law of exponent -0.88

Source: Salat, Bourdic 2015.

leveraged huge amounts of private investment. Land value capture has allowed financing further investments in transit.

\section{Towards an efficient space economy form for Shanghai}

While Shanghai's population is suburbanizing (Fig. 19), its firms are not decentralizing anywhere near to the same degree. Employment density is highly concentrated within the Outer Ring Road with highest

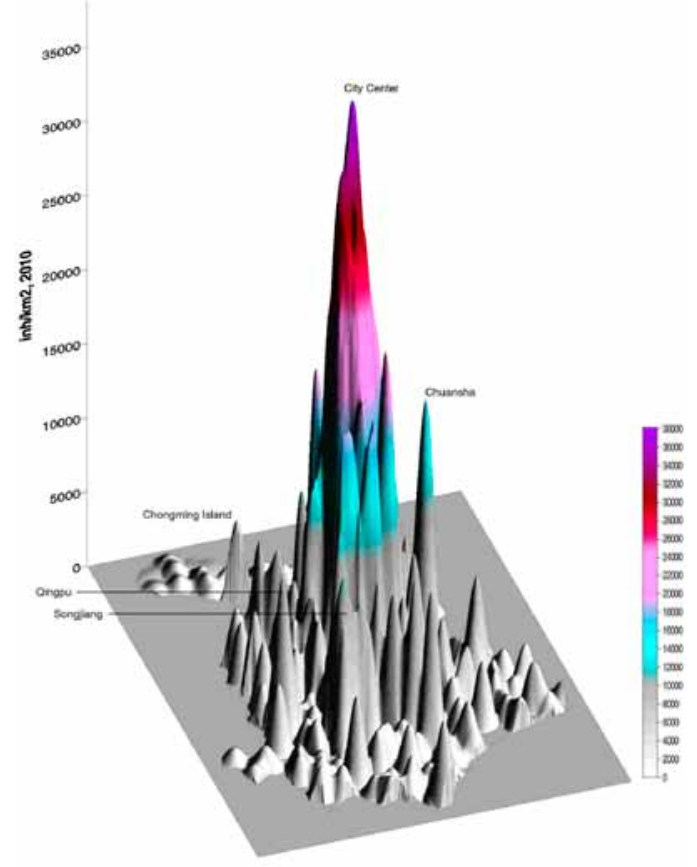

Fig. 19. 3D visualization of people density in Shanghai Source: World Bank and Chreod Ltd. 2015. densities in the central area (Figs 20-22). Medium densities are found in the Jiading corridor to the north, southwest of the inner core beyond the Outer Ring Road in Minhang District, and south of Hongqiao airport. However, these densities are still very low compared to the inner core. Job/population ratios are therefore high in in the central area, but extremely low elsewhere in Shanghai.

Many of the resources necessary for global economies are not hyper-mobile and are embedded in highly interconnected relatively small places. In particular, networks of highly-specialized interlinked companies are localized in urban space and develop specific place cultures. As stated by Sassen (2005): "Recapturing the geography of places involved in globalization allows us to recapture people, workers, communities, and more specifically, the different work cultures, besides the corporate culture, involved in the work of globalisation".

As we have already remarked, this geography of places is shaped in global cities by the structure and level of transit accessibility. Shanghai would thus benefit coordinating spatial planning and provision of transit infrastructure in order to match peaks of jobs densities with peaks of transit accessibility with a polycentric form similar to Tokyo's. Shanghai Line 4 (Figs 23 and 24 ) is the same size as Yamanote line and defines the

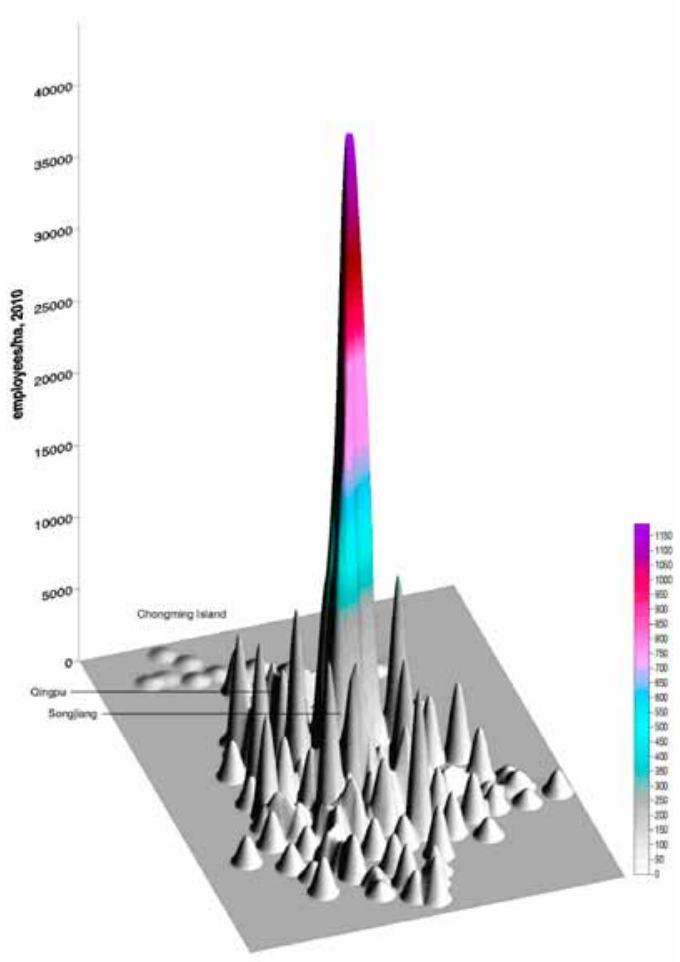

Fig. 20. 3D visualization of jobs density in Shanghai Source: World Bank and Chreod Ltd. 2015. 


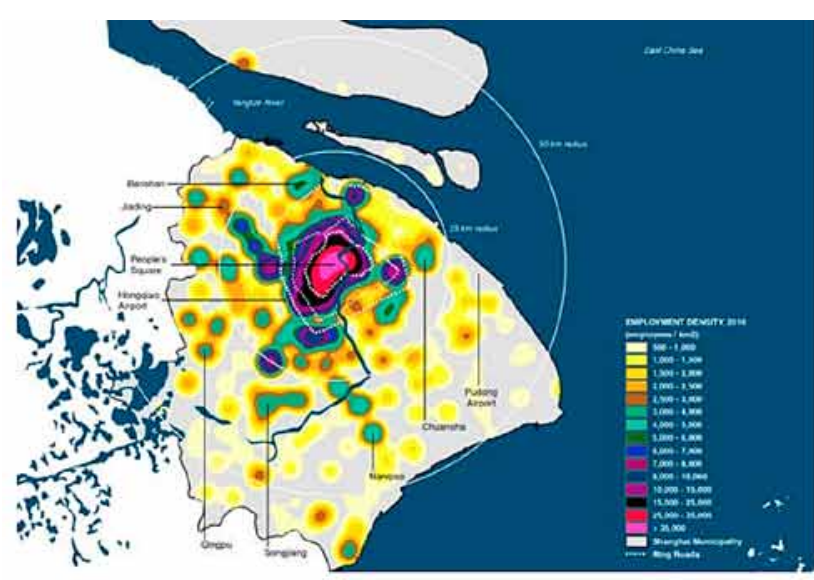

Fig. 21. Shanghai employment densities, 2010

Source: World Bank and Chreod Ltd. 2015

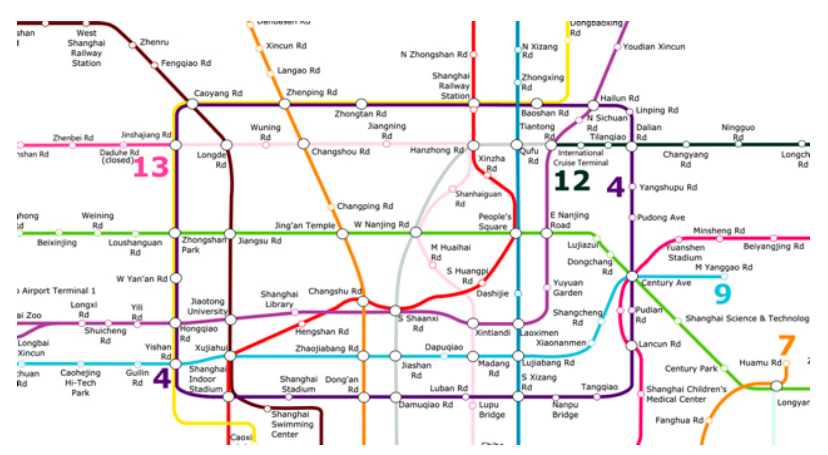

Fig. 23. Shanghai subway core in 2015

core of Shanghai. Within the loop, the clustering of high-ranking hubs is increasing but the loop itself remains a less structured system than Tokyo's Yamanote sen or London's Circle line. To achieve a shape similar to those global cities, Shanghai would benefit strengthening hierarchies in urban space and in urban networks, and prioritising economic concentration in its inner core while strengthening strong economic nodes along subway line 4 that could play the same role as Yamanote line in Tokyo or Circle line in London.

Analysis of centralities within Shanghai subway network allows identifying areas of opportunity along subway lines 4 and 2, as shown in Figure 25, which shows the hierarchy of betweenness centralities in Shanghai subway.

Figure 26 shows travel times from People Square with subway lines as planned for 2020. It reflects the map of closeness centralities of stations and shows that the inner core is the most accessible area of the city at 30 minutes by transit (in purple), and thus the natural place for concentrating efficiently firms and jobs growth. The hierarchy of betweenness centralities in Shanghai (Fig. 25) brings an important supplementary information. It shows the highest potential areas of opportunity along lines 4 and 2, with a pattern similar to Tokyo or London's pattern. In London, these between central stations ar-

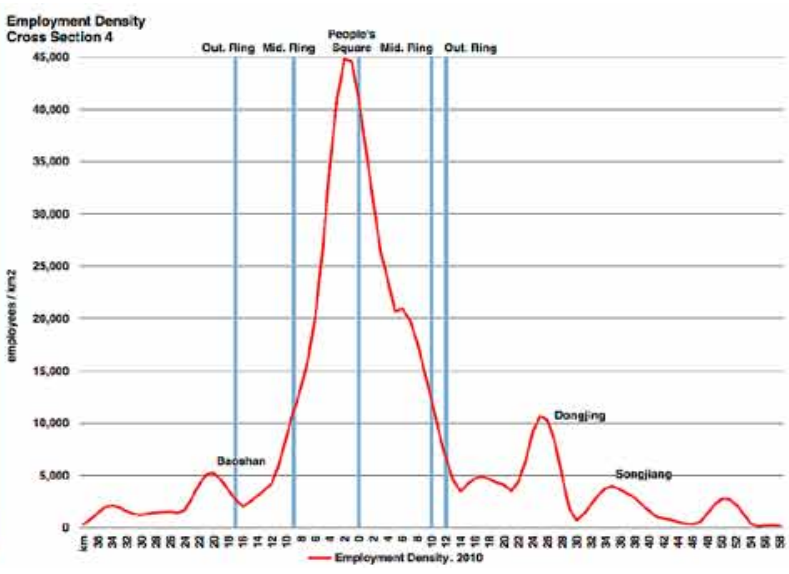

Fig. 22. Shanghai employment densities along a cross section, 2010

Source: World Bank and Chreod Ltd. 2015

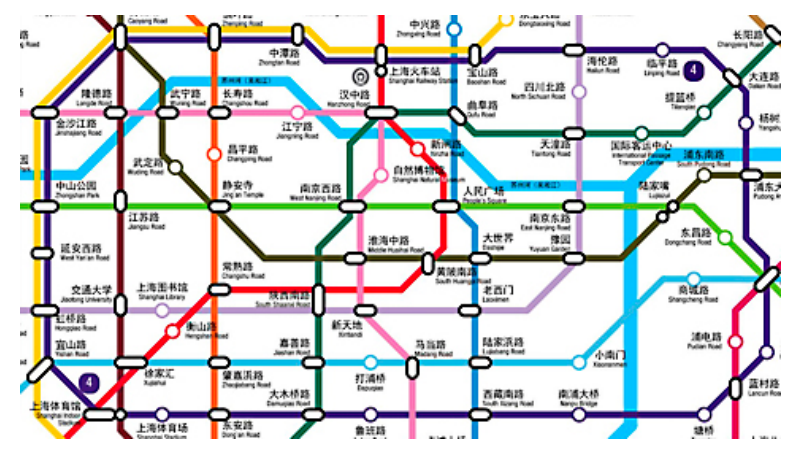

Fig. 24. Shanghai subway core in 2020 shows an increase in degree and betweenness centralities in Shanghai core with high potential stations in particular along the loop line 4

ticulating different parts of the network are strategically developed as "areas of opportunity" to leverage private investment with public investment in infrastructure and improvement of public realm. In Tokyo, they are booming sub-centres. In both cities, the subway network centralities connect the city at a higher scale with the HSR network. Tokyo station and King's Cross in London are both centralities in the subway network and major HSR stations. King's Cross, for example, was an unbalanced node, with one of the highest accessibilities, connectivity and centrality in Europe, UK and London, for HSR, national and regional rail, urban rail and subway networks, and with Crossrail 1 and 2 coming, the area had a strong unbalance and underutilization of its 27 ha of land and was an area of opportunity for redevelopment and creation of a high-tech industries hub with in particular the locational choice of Google second global headquarter ${ }^{9}$ (Salat, Ollivier 2017).

9 Creating place value with high quality public realm (40\% of the land), 20 new connective streets, 10 plazas and gardens, and a mixed-use program including Google second global headquarters, digital startups but also inclusionary housing and a major school of arts, cafes and retail, fostered high market values. 


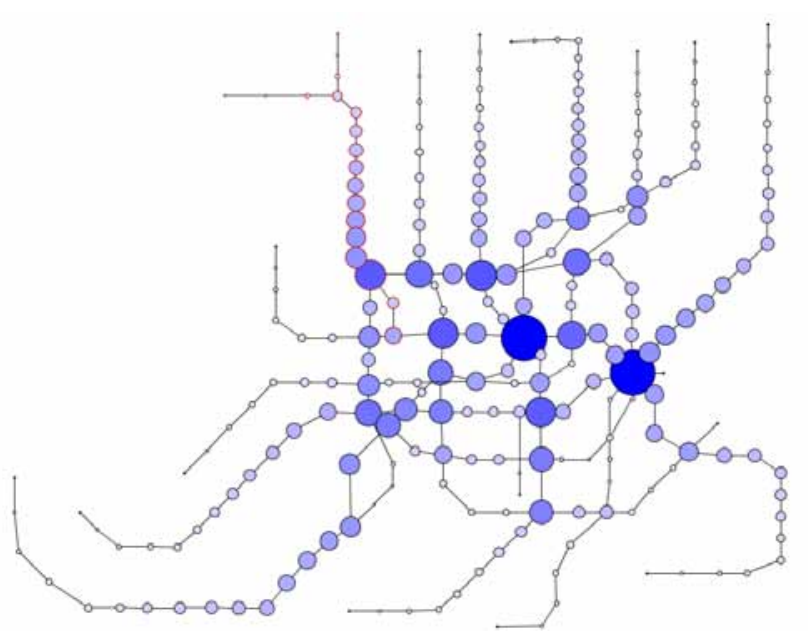

Fig. 25. The hierarchy of betweenness centralities in Shanghai subway

Source: Salat 2015

Shanghai rail Station in Puxi could have a similar potential if an HSR (High Speed Rail) station was developed with FAR ${ }^{10}$ (Floor Area Ratio) of 5 similar to Tokyo station allowing high density commercial real estate development in an area connected through many scales. A major urban upgrade of its surroundings improving connectivity and access could make Shanghai Station a very attractive area.

To reap the opportunities created by its massive investments in the subway network, Shanghai would benefit from a better coordination between intensity of land use and economic policies by: 1) encouraging development in the major interchanges (highest degree centralities), in the most accessible stations of the network (highest closeness centrality), and in the stations that are major articulations of the network (highest betweenness centralities); 2) moderating development in the areas that are less accessible within the network; 3) discouraging development in areas that are more than 1 kilometre from a subway station. Developed by the World Bank with the support of the Urban Morphology Institute, the 3V Framework, articulates the interplay of Node Value (centrality in the network), Place Value (quality of urban fabric), Market Potential Value (market readiness and demand-supply balance) with a systematic set of metrics to identify most promising areas of opportunity for prioritizing urban renewal or development, and shaping efficiently the urban space economy (Salat, Ollivier 2017).

Aligning intensity of land development with transit accessibility would require a substantial shift

${ }^{10}$ Floor area ratio (FAR) (also floor space ratio (FSR), floor space index (FSI), site ratio and plot ratio) is the ratio of a building's total floor area (gross floor area) to the size of the piece of land upon which it is built.

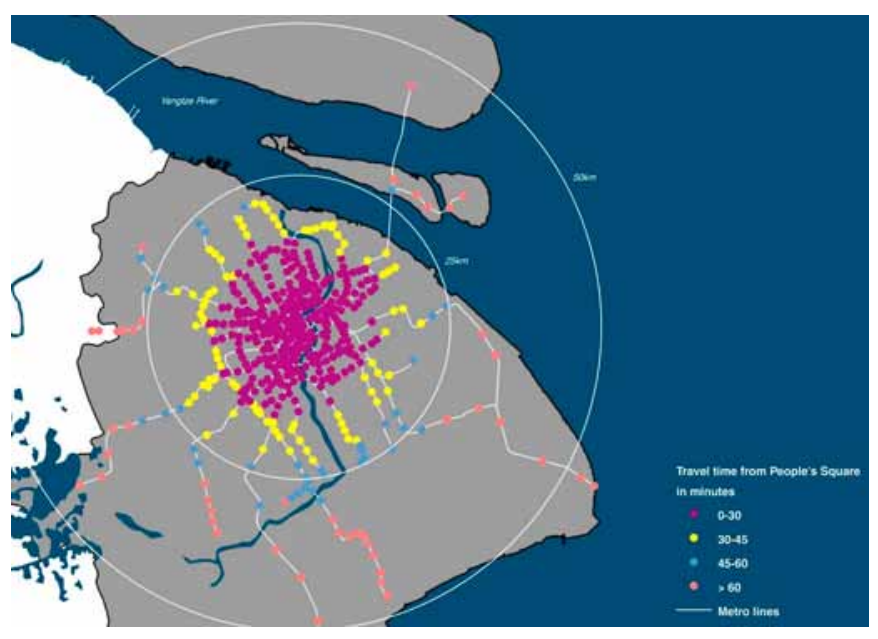

Fig. 26. Map of travel times from People Square in Shanghai municipality with the subway lines planned for 2020 in minutes. In purple: 0-30; in yellow: $30-45$; in blue: $45-60$; in orange: above 60

Source: World Bank and Chreod Ltd. 2015

from Shanghai planning practices of the last decades. Shanghai enormous spatial expansion between 2000 and 2010 has happened at low density with little coordination with subway network development, as shown in Figure 27, raising issues of transit accessibility and of congestion, and leading to diseconomies of agglomeration. While $16 \%$ of built up land in 2000 was within a 500 -meter radius of a subway station, only $3 \%$ of newly built up land is within this radius (World Bank, Chreod Ltd. 2015). Many areas that densified during the past decade are not served by subway. Moreover, Shanghai has built in a decade an additional land area of $1,516 \mathrm{~km}^{2}$, roughly equal to the double of the area of New York City and to the entire area of Greater London (World Bank, Chreod Ltd. 2015), with an urban pattern of superblocks (of size around half-kilometre side). The density of 12 street intersections/ $\mathrm{km}^{2}$ in the new urbanised area (Fig. 28) added to Shanghai built land area between 2000 and 2010 is typical of highly energy intensive superblocks with little pedestrian accessibility. As a comparison, UN-Habitat recommends dense patterns of streets with at least 80 to 100 intersections $/ \mathrm{km}^{2}$ and $18 \mathrm{~km}$ of streets $/ \mathrm{km}^{2}$ (Salat et al. 2011; Salat, Ollivier 2017; Salat et al. 2017; UN Habitat 2014)

A policy instrument to align land use intensity of development with transit accessibility is fine-tuned zoning policies. First, it is encouraged that FAR be set at different levels depending on uses and on accessibility. For example, Seoul zoning regulations set FARs as high as 10 for commercial uses around the most connected and central transit stations, of between 2 and 4 for mixed residential and business areas, and between 1 and 2 for residential uses; uses are defined with a fine 


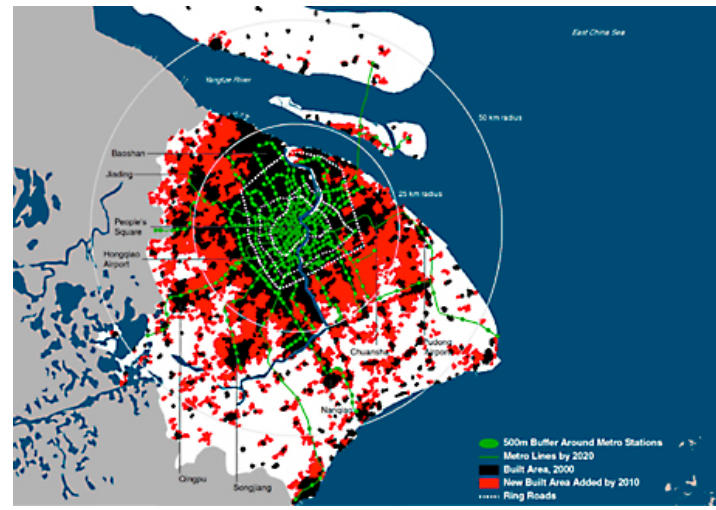

Fig. 27. Map of Shanghai built up land in 2000 and 2010 with planned subway network

Source: World Bank and Chreod Ltd. 2015.

granularity depending on proximity to and importance of transit stations. This creates a varied city juxtaposing residential and quiet neighbourhoods in close proximity to thriving business districts. Manhattan East Midtown rezoning is also based on adjacency to transit. It includes FAR of 24 for highly accessible areas directly around Grand Central Terminal, 21.6 FAR along Park Avenue, and 18/14.4 FAR in other areas to the east and west (New York City Department of City Planning 2013). Second, it is recommended that FARs in Shanghai include a margin of flexibility both for transferring FAR between uses according to market changes and for allowing private sector to adjust intensity of development to market needs ${ }^{11}$.

\section{Shanghai as a node within the structure of global flows versus Singapore and Hong Kong}

In only three decades, China has strategically opened and transformed itself from a closed society to the world's largest goods exporter. However, McKinsey ranks China as only the $25^{\text {th }}$ most connected country in the world, five places higher than it was in 1995 (Manyika et al. 2014). McKinsey considers China to

\footnotetext{
11 This has been applied in London's Kings Cross with margins of flexibility between uses up to $20 \%$. It increases the marketability of real estate operations in developments that take years to be completed. This margin of flexibility can also be used to capture part of the value created by real estate development to finance transit infrastructure provision, public space and affordable housing. For example, adapted zoning in Hudson Yards sets varied FAR for predominantly commercial (FAR 10 to 33), mixed use (FAR 6.5 to 12 ), and predominantly residential (6 to 15) with a range between base and maximum FAR, in order to introduce flexibility and capture value. Developers which want to build over base FAR and up to maximum FAR (for example between base FAR 10 and maximum FAR 33 for commercial use in the densest blocks), can do so by paying bonus payments into the zoning-based District Improvement Fund (DIF). This creates an additional real estate opportunity and allows for demand driven development. DIF can be used to finance subway lines extensions, public space and inclusionary housing, creating a positive feedback loop of development.
}

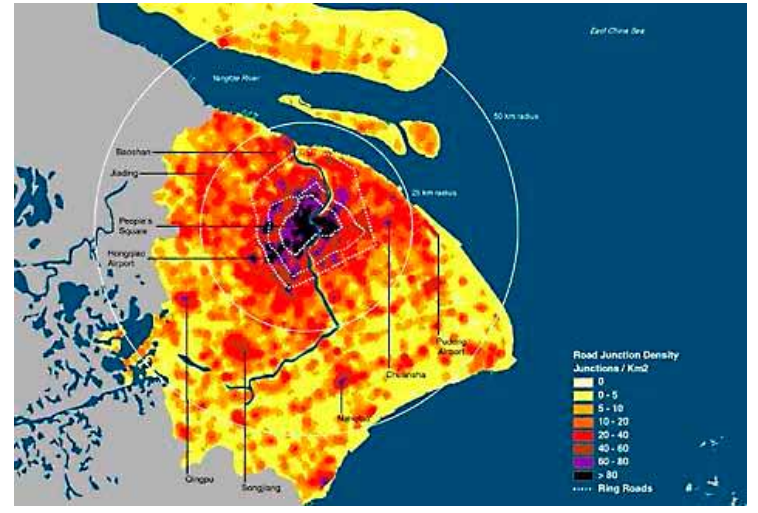

Fig. 28 Map of street intersections density in Shanghai in 2010 Source: World Bank and Chreod Ltd. 2015.

be a specialist country in the global connectedness landscape given its relative strength in goods and financial flows, in which it ranks $5^{\text {th }}$ and $6^{\text {th }}$, respectively, roughly on par with the United States. However, China scores lower on services flows (ranked $21^{\text {st }}$ ), on people flows (ranked $93^{\text {rd }}$ ), and on data and communication (ranked $33^{\text {rd }}$ ). Shanghai may find in the coming decade its business model specialized in goods flows be a limit to becoming a global city in a new era dominated by knowledge-intensive flows and digitization.

\section{The global rise of the knowledge economy}

Fast growing knowledge-intensive economy puts China and Shanghai business model at risk. Global flows are increasingly digital and knowledge based. Cross-border Internet traffic increased 18 -fold between 2005 and 2012. Knowledge-intensive trade grows 1.3 times as fast as labour-intensive goods. The value of knowledge-intensive flows together reached $\$ 12.6$ trillion in 2012, nearly half the combined total value of goods, services, and financial flows and more than the combined 2012 GDP of China and Germany (Manyika et al. 2014). This reveals the global rise of knowledge economy.

Beyond its spatial transformation, Shanghai challenge for the next decades is to become a waypoint across five types of flows: goods, services, finance, people, and data and communication. Most important for Shanghai connectedness strategy is the evolution in the composition, source, and destination of global flows. Flows of knowledge-intensive goods are expected by McKinsey to continue to outpace flows of labour-intensive goods. Knowledge-intensive goods now represent nearly half of total goods trade, and they may represent the significant majority of goods trade by 2025 (Manyika et al. 2014). The imperative for Shanghai policy makers is to fully embrace this new 
growth era and ensure that its economy is positioned to benefit from it. The more open Shanghai will be to global inflows and outflows of goods, services, finance, data, communication and people, the greater the economic benefits will be. The new connectivity will not connect raw material, energy and cheap manpower together to produce goods. It will connect highly skilled people through continents to exchange information.

\section{The benefits of being a waypoint: the combined flows value of Hong Kong and Singapore are equal to those of Japan, and represent about half of those of the US (47\%) and of mainland China (51.4\%).}

Hong Kong and Singapore rank high in all the dimensions of connectedness (Manyika et al. 2014). Singapore is a small country that ranks far above its weight in global trade, primarily by acting as an intermediary of flows moving between other countries. Although its population was only 5.3 million in 2012, its GDP was US $\$ 275$ billion, making it the world's 35th-largest economy. Singapore's high connectivity $\left(4^{\text {th }}\right.$ overall) is mainly driven by its flow intensity - the value of flows relative to the size of the economy - of $436 \%{ }^{12}$. Singapore's role as a major waypoint is further reflected in its above-average level of connectedness to people and data flows. In 2010, nearly two million foreign-born nationals lived in Singapore, out of a population of just over five million. Singapore ranks eleventh on cross-border Internet traffic, which grew at $67 \%$ a year between 2005 and 2013, compared with a global average of $46 \%$. Singapore also has one of the world's highest Internet penetration rates at $88 \%-$ higher than the $82 \%$ average for developed economies. Singapore ranks $2^{\text {nd }}$ in goods, $3^{\text {rd }}$ in services, and $4^{\text {th }}$ in financial, and $5^{\text {th }}$ in data and communication, with flows value of 1,198 US\$ billion, equivalent to the entire flows value of Russia (Manyika et al. 2014).

The long-term vision for Hong Kong to strengthen its position as Asia's world city was spelt out by the Commission on Strategic Development in its report entitled "Bringing the Vision to Life - Hong Kong's Long-term Development Needs and Goals" published in 2000. It says: "Hong Kong should not only be a major Chinese city, but could become the most cosmopolitan city in Asia, enjoying a status comparable to that of New York in North America and London in Europe". London boasts itself for being a place where one hundred languages are spoken and for being the $4^{\text {th }}$ or $5^{\text {th }}$ French city. One third of its employees are foreigners.

\footnotetext{
12 As a comparison Germany has a flow intensity of $110 \%$, China $62 \%$, Mexico, 78\%, and India, 61\% (Manyika et al. 2014).
}

Hong Kong ranks $1^{\text {st }}$ in goods connectedness, $4^{\text {th }}$ in services, and $3^{\text {rd }}$ in financial, with a flow intensity of $546 \%$ and flows value of 1,437 billion, equal to the entire flows value of the United Kingdom. Hong Kong is a global hub for trade and finance. The city's economy is based around logistics, trade-related services, finance and tourism and has experienced rapid growth in recent years, with per capita GVA increasing by $51 \%$ between 1993 and 2010 (Berube, Rode 2010). Hong Kong's economic strengths as a logistics and financial centre rely on efficient transport networks and good regional and international links. The extremely high densities of both residences and workplaces in the city have allowed for easy opportunities for face-to-face interaction required in financial centres and efficient connections between businesses and global networks.

\section{Shanghai would benefit a diversification of its flows and embracing the new opportunities of digitization}

Since 2010, Shanghai is the world's largest container port, with a recorded volume of 32.5 million containers (TEUs) in 2012 (Hong et al. 2013). At global scale, Shanghai has replaced Pusan as the port hub of Asia. Shanghai was outside the top 25 in 1990 but by 2011 was the largest port in the world in terms of container traffic, marginalizing Japanese ports and becoming with Ningbo the most important cluster of global ports after the cluster Hong Kong-Shenzhen-Guangzhou. Shanghai and the two major trans-shipment hubs of Singapore and Hong Kong are now home to the largest container-shipping ports in the world, with each processing around $5 \%$ of total global container volume.

Although Shanghai is today the first global port, the city did not achieve the same rankings in other dimensions of connectedness. Shanghai lags behind US and Europe cities in terms of air connectivity, which reflects the level of participation in knowledge and advanced services economy. The global network of air connectivity is still articulated by the major hubs and central cities that are New York, London and Tokyo. Shanghai ranks only $21^{\text {st }}$ in airport traffic, which reflects goods, services and people connectedness while Beijing is the gateway to China and the second world airport before London $\left(3^{\text {rd }}\right)$ and Tokyo $\left(4^{\text {th }}\right)$. Although home of two major airports, Shanghai for increasing its participation in global value chains and in the global advanced services economy needs to improve further its air connectivity, and integrate it seamlessly, like Amsterdam, with HSR and subways, as part of its overall competitiveness strategy.

Shanghai ranks $16^{\text {th }}$ as financial centre and is below the $25^{\text {th }}$ rank in online traffic. The first Chinese city, 
Beijing, ranks $24^{\text {th }}$ in online traffic. Shanghai would immensely benefit improving its digital connectivity. Digitization expands opportunities to participate in the global economy. Digitization is transforming global flows in three ways: 1) by changing tangible flows into digital flows with lower costs of access, transport, and marginal production, and by turning some physical flows of people into virtual flows; 2) by enhancing physical flows - making them more manageable and, in many cases, more valuable - through the addition of "digital wrappers"; 3) By creating online platforms that facilitate production and cross-border exchanges (Manyika et al. 2014). Shanghai's position in goods flows may be challenged by this digitization. Shanghai needs to adapt to a fast-changing world offering new opportunities to sell and source products, services, and ideas across borders. Shanghai must embrace the new business models made possible by the power of digitization. Marginal cost economics of digitization reduce costs associated with access, discovery, and distribution of goods and services to nearly zero. As a result, the cost of participating in global flows is lowered for Shanghai individuals, small firms, and entrepreneurs. This is already leading in advanced global economies to the emergence of micro-multinationals, micro-work, and micro-supply chains that are able to tap into global opportunities (Manyika et al. 2014).

\section{Conclusions: cities in global networks, structures of interdependence}

The deep economic histories of major cities and city-regions matter more in today's global economy than they did in the Keynesian period geared towards national territorial convergence and standardisation (Sassen 2006). The patterns of ordered complexity that we have observed at all scales in global cities point to another dimension than competition; they are the "signature" of interdependence, where no single global city can be considered in isolation but where they are all part of a global system structured by the mathematical regularities discovered by network theory. The "universality classes" in the system's organisation reflect processes of emergence where the chaos of a myriad of decisions becomes synchronized by a flexible but mathematically precise pattern of efficient systemic architecture. In this systemic perspective, the global cities as complex networks at intra-urban scale and as networks of global cities are much more than a set of intra urban locations in competition to attract flows or a network of cross-border flows connecting cities. It is a "complex, highly specialized organisational infrastructure for the management and servicing of the leading economic sectors" (Sassen 2006). The special- ised differences within cities and among cities take on renewed value in this organisational infrastructure.

Overemphasizing competition may thus lead for an emerging global city like Shanghai to missed opportunities, such as developing parallel networked inter-city policy initiatives centred on the growing economic importance of inter-city networks for firms and markets. For example, recent research shows a multiplication of business networks between Shanghai and its immigrant community in Tokyo (Sassen 2006). To become global in a world of interdependent cities, Shanghai would benefit building collaborative bridges with other major global cities and promote the message of the larger and more globalised hubs. This requires both physical and digital linkages putting Shanghai as a key connecting hub in people, services, financial, data and communication connectivity at the articulation of different markets. To become global, Shanghai will need to adjust to the new world of global flows, dominated by knowledge-intensive goods and services, by a torrent of data that is transforming cross-border activity, and by the economic promise of digitization. Shanghai global connectedness and spatial structure needs to adapt to an increasingly connected, knowledge-intensive, and digitized world, where interaction and communication between people matters more than physical flows. Shanghai could tremendously benefit from an active participation in knowledge-intensive flows if it builds a central position and becomes a waypoint in the global economy like London, New York, Tokyo, Hong Kong and Singapore.

\section{References}

Barabási, A.-L.; Albert, R. 1999. Emergence of scaling in random networks, Science 286: 509-512. https://doi.org/10.1126/science.286.5439.509

Barabási, A. I.; Frangos, J. 2002. Linked: the new science of networks. 1st edition. Cambridge, Mass: Perseus Books Group.

Barabási, A.-L.; Newman, M.; Watts, D. J. 2006. The structure and dynamics of networks. USA: Princeton University Press.

Batty, M. 2013. The new science of cities. Cambridge, Massachusetts: The MIT Press.

Berube, A.; Rode, P. 2010. Global MetroMonitor: the path to economic recovery [online], [cited 17 June 2016]. Available from Internet: https://www.brookings.edu/research/global-metromonitor-the-path-to-economic-recovery

Bourdic, L. 2011. Urban density and private transport energy consumption - from global trends to local solutions: Master thesis. Center for Environmental Policy. Imperial College London.

Braudel, F. 1984. The perspective of the world. New York: Harper and Row.

Castells, M. 1989. The informational city: information technology, economic restructuring, and the urban-regional process. Oxford: Basic Blackwell. 
Curtis, S. 2010. Global cities and the transformation of the International System, Review of International Studies 37(4): 1923-1947. https://doi.org/10.1017/S0260210510001099

Chorus, P.; Bertolini L. 2011. An application of the node place model to explore the spatial development dynamics of station areas in Tokyo, The Journal of Transport and Land Use 4(1): 45-58. https://doi.org/10.5198/jtlu.v4i1.145

Dobbs, R.; Smit, S.; Manyika, J.; Roxburgh, C.; Restrepo, A. 2011. Urban world: mapping the economic power of cities. McKinsey Global Institute.

Hong, Z.; Merk, O.; Nan, Z.; Li, J.; Mingying, X.; Wenqing, X.; Xufeng, D.; Jinggai, W. 2013. The competitiveness of global port-cities: the case of Shanghai, China. OECD Regional Development Working Papers.

Manyika, J.; Bughin, J.; Lund, S.; Nottebohm, O.; Poulter, D.; Jauch, S.; Ramaswamy, S. 2014. Global flows in a digital age. McKinsey \& Company.

New York City Department of City Planning, 2013. Proposed East Midtown text amendment.

Pareto, V. 1896. La Courbe de la Répartition de la Richesse, in G. Busino (Ed). Oeuvres Complètes de Vilfredo Pareto. Librairie Droz, Geneva.

Rausas, M. P. du; Manyika, J.; Hazan, E.; Bughin, J.; Chui, M.; Said, R. 2011. Internet matters: the Net's sweeping impact on growth, jobs, and prosperity. McKinsey Global Institute.

Roth, C.; Kang, S. M.; Batty, M.; Barthelemy, M. 2012. A longtime limit for world subway networks, Journal of The Royal Society Interface (in press). https://doi.org/10.1098/rsif.2012.0259

Salat, S.; Labbé, F.; Nowacki, C. 2011. Cities and forms. On sustainable urbanism. Hermann, Paris.

Salat, S. 2015. Shanghai in the world economy in 2050. Connecting people to people through scales. Report for the World Bank. Urban Morphology and Complex Systems Institute, Paris.

Salat, S.; Bourdic, L. 2015. L'Économie spatiale du Grand Paris Connectivité et création de valeur. Urban Morphology Institute and Complex Systems Institute and Caisse des Dépôts.

Salat, S. 2017. A systemic approach of urban resilience: power laws and urban growth patterns, International Journal of Urban Sustainable Development (in press). https://doi.org/10.1080/19463138.2016.1277227

Salat, S.; Bourdic, L.; Kamiya, M. 2017. Economic foundations for sustainable urbanization: a study on three-pronged ap- proach: planned city extensions, legal framework, and $m u$ nicipal finance. Nairobi: UN-Habitat.

Salat, S.; Ollivier, G. 2017. Transforming the urban space through transit-oriented development: the $3 \mathrm{~V}$ Approach. World Bank. Washington, DC.

Sassen, S. 1991. The Global City: New York, London, Tokyo. Princeton: Princeton University Press.

Sassen, S. 2000a. Digital networks and the state: some governance questions, Theory, Culture, and Society 17: 19-33. https://doi.org/10.1177/02632760022051293

Sassen, S. 2000b. Spatialities and temporalities of the global elements for theorization, Public Culture 12: 215-32. https://doi.org/10.1215/08992363-12-1-215

Sassen, S. 2000c. Territory and territoriality in the global economy, International Sociology 15: 372-93. https://doi.org/10.1177/0268580900015002014

Sassen, S. 2005. The Global City: introducing a concept, Brown Journal of World Affairs XI (2): 27-43.

Sassen, S. 2006. Locating cities in global networks: Tokyo and regional structures of interdependence, The Asia Pacific Journal 4(8): 0.

Sivaev, D. 2013. Inner London's economy. A ward-level analysis of the business and employment base. Center for Cities.

The Economist Intelligence Unit. 2013. Hot spots 2025 Benchmarking the future competitiveness of cities. A report from the Economist Intelligence Unit.

UK Office for National Statistics 2009. Briefing Note.

UN Habitat. 2014. A new strategy of sustainable neighbourhood planning: five principles. Discussion Note 3. Urban Planning.

World Bank \& Chreod Ltd. 2015. Spatial transformation of Shanghai to 2050. Final Report prepared for the World Bank, December 2015.

\section{SERGE SALAT}

is an architect, urban planner, scientist, and historian. He is President of the Urban Morphology and Complex Systems Institute, Paris. He has worked on network analysis and complexity science in urban studies, spatial planning and spatial economics. He advises United Nations and international organizations on urban policies transitions. 